\title{
Using Hob Offset to Balance Dynamic Strength in Spur Gears
}

Chuen-Huei Liou and Hsiang Hsi Lin

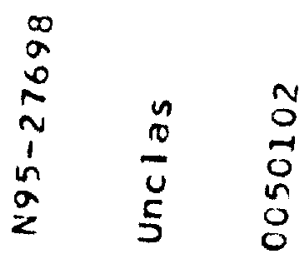

The University of Memphis

Memphis, Tennessee

and

Fred B. Oswald and Dennis P. Townsend

Lewis Research Center

Cleveland, Ohio

Prepared for the

31st Joint Propulsion Conference and Exhibit cosponsored by AIAA, ASME, SAE, and ASEE San Diego, California, July 10-12, 1995

$M=7$

2 (1) 


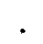

. 
and using the AGMA formulation. Mabie, Rogers, and Reinholtz (1990) developed a numerical procedure to determine the hob offsets for a pair of gears to maximize the ratio of recess to approach action, to balance tooth strength of pinion and gear, to maintain the desired contact ratio, and to avoid undercutting.

The earlier analyses summarized above dealt primarily with the static tooth strength of pinions and gears. They used the Lewis formula (Shigley and Mitchell, 1983) to calculate the tooth root stress and based calculations on the maximum static load applied at the tip of the tooth. The dynamic tooth load, especially at high speed, can be significantly greater than the static load, and the maximum dynamic tooth load may occur at a location other than the tooth tip (Lin et al., 1989). Furthermore, gears produced by offset hob cutters may have transmission errors different from gears with standard tooth proportions. The dynamic response of a gear system, excited by the dynamic transmission error, can be considerably different for nonstandard gears. To design high speed gears of balanced tooth strength, dynamic effects should be considered.

This paper presents an investigation of the combined effect of hob offset and gear speed on dynamic load and tooth bending stress. It represents an extension of the earlier static analyses. A new version of the computer program DANST (Oswald et al., 1993) was used for the analysis.

\section{Theory and Analysis}

\section{Spur Gears Cut by a Hob Cutter}

The following analysis is based on the study of Mabie and Reinholtz (1987). Figure 1 shows a hob cutting a pinion where the solid line indicates a pinion with fewer than the minimum number of teeth required to prevent interference. The addendum line of the hob falls above the interference point $E$ of the pinion so that the flanks of the pinion teeth are undercut. To avoid undercutting, the hob can be withdrawn a distance e so that the addendum line of the hob passes through the interference point E. This condition is shown dotted in Fig. 1 and results in the hob cutting a pinion with a wider tooth. As the hob is withdrawn, the outside radius of the pinion must also be increased (by starting with a larger blank) to maintain the same clearance between the tip of the pinion tooth and the root of the hob tooth. To show the change in the pinion tooth more clearly, the withdrawn hob in Fig. 1 was moved to the right to keep the left side of the tooth profile the same in both cases.

The width of the enlarged pinion tooth on its cutting pitch circle can be determined from the tooth space of the hob on its cutting pitch line. From Fig. 2, this thickness can be expressed by the following equation:

$$
t=2 \mathrm{e} \tan \phi+\frac{p}{2}
$$

Equation (1) can be used to calculate the tooth thickness on the cutting pitch circle of a gear generated by a hob offset an amount $e$; e will be negative if the hob is advanced into the gear blank. In Fig. 1, the hob was withdrawn just enough so that the addendum line passed through the interference point of the pinion. The withdrawn amount can be increased or decreased as desired as long as the pinion tooth does not become undercut or pointed. The equation that describes the relationship between $e$ and other tooth geometry is

$$
e=A B+O A-O P=\frac{k}{P_{d}}+R_{b} \cos \phi-R_{p}
$$

Therefore,

$$
\begin{gathered}
e=\frac{k}{P_{d}}-R_{p}\left(1-\cos ^{2} \phi\right) \\
e=\frac{1}{P_{d}}\left(k-\frac{N}{2} \sin ^{2} \phi\right)
\end{gathered}
$$

Two equations that were developed from involutometry find particular application in this study:

$$
\begin{gathered}
\cos \phi_{B}=\frac{R_{A}}{R_{B}} \cos \phi_{A} \\
t_{B}=2 R_{B}\left(\frac{t_{A}}{2 R_{A}}+\operatorname{inv} \phi_{A}-\operatorname{inv} \phi_{B}\right)
\end{gathered}
$$

By means of these equations, the pressure angle and tooth thickness at any radius $R_{B}$ can be found if the pressure angle and tooth thickness are known at a reference radius $R_{A}$. This reference radius is the cutting pitch radius and the tooth thickness on this cutting pitch circle can be easily calculated for any cutter offset by Eq. (1). The reference pressure angle is the pressure angle of the hob cutter.

When two gears, gear 1 and gear 2, which have been cut with a hob offset $e_{1}$ and $e_{2}$, respectively, are meshed together, they operate on pitch circles of radii $R_{1}$ and $R_{2}$ and at pressure angle $\phi^{\prime}$. The thickness of the teeth on the operating pitch circles can be expressed as $t_{1}$ and $t_{2}{ }_{2}$ which can be calculated from Eq. (6). These dimensions are shown in Fig. 3 together with the thickness of the teeth $t_{1}$ and $t_{2}$ on the cutting pitch circles of radii $R_{1}$ and $R_{2}$. 


\title{
USING HOB OFFSET TO BALANCE DYNAMIC STRENGTH IN SPUR GEARS
}

\author{
Chuen-Huei Liou and Hsiang Hsi Lin \\ The University of Memphis \\ Memphis, Tennessee \\ and \\ Fred B. Oswald and Dennis P. Townsend \\ National Aeronautics and Space Administration \\ Lewis Research Center \\ Cleveland, Ohio
}

\begin{abstract}
This paper presents an analytical study on the effect of hob offset on the dynamic tooth strength of spur gears. The study was limited to equal and opposite offset values applied to the pinion and gear to maintain the standard operating center distance. The analysis presented in this paper was performed using a new version of the NASA gear dynamics code DANST.

The operating speed of the transmission has a significant influence on the amount of hob offset required to equalize the dynamic stresses in the pinion and gear. In the transmission studied, at low speeds, the optimum hob offset value was found to fluctuate. At higher speeds, the optimum value was constrained by the minimum allowed thickness at the tip of the pinion tooth. For gears that must operate over a range of speeds, an average offset value may be used. Spur gears designed with the procedure presented here can have significant improvements in load capacity.
\end{abstract}

\section{Nomenclature}

\footnotetext{
e hob offset, $m$ (in.)

k hob addendum parameter

m module, $\mathrm{mm}$

$\mathrm{N}$ number of teeth

p circular pitch, $m$ (in.)

$P_{d} \quad$ diametral pitch, in. ${ }^{-1}$

$R_{b} \quad$ base radius, $m$ (in.)

$R_{p} \quad$ Pitch radius, $m$ (in.)

t tooth thickness, $m$ (in.)

$\phi \quad$ pressure angle, degree
}

Subscript
$1 \quad$ driving gear (pinion)
$2 \quad$ driven gear (gear)

Introduction

Designing gear transmission systems involves selecting combinations of gears to produce a desired speed ratio. If the ratio is not unity, the gears will have different diameters. The tooth strength of the smaller gear (the pinion) is generally weaker than that of the larger one (the gear) if both are made of the same material. In some designs, the pinion must have a very small number of teeth in order to provide the required ratio and fit in the available space. This can lead to undercut of the teeth in the pinion which further reduces strength.

One solution to the pinion design problem is to specify nonstandard gears in which the addendum of the pinion is increased slightly, thus increasing its strength, while the gear addendum may be decreased by an equal amount. These changes in tooth proportions may be accomplished without changing operating center distance and with standard cutting tools by withdrawing the cutting tool slightly as the pinion blank is cut and advancing the cutter the same distance into the gear blank. This practice is called the long and short addendum system. When gears are cut by hobs, this adjustment to the tooth proportions is called hob cutter offset.

Several studies have been performed to determine the proper hob cutter offset to produce gear pairs of different sizes and contact ratios with balanced tooth strength. Walsh and Mabie (1971) investigated using hob offset to equalize the stress in the pinion and gear teeth. They developed hob offset charts for various velocity ratios and for several values of center distance. Mabie, Walsh, and Bateman (1983) performed similar but more detailed work about tooth stress equalization and compared the results with those found from the Lewis form factor $y$ 
To determine the pressure angle $\phi^{\prime}$ at which these gears will operate, we found

$$
\frac{\omega_{2}}{\omega_{1}}=\frac{N_{1}}{N_{2}}=\frac{R_{1}}{R_{2}}
$$

and

$$
t_{1}+t_{2}=\frac{2 \pi R_{1}}{N_{1}}=\frac{2 \pi R_{2}}{N_{2}}
$$

Substituting Eq. (6) into Eq. (8) and dividing by $2 R_{1}^{\prime}$,

$$
\begin{array}{r}
{\left[\frac{t_{1}}{2 R_{1}}+\left(\operatorname{inv} \phi-i n v \phi^{\prime}\right)\right]+\frac{R_{2}}{R_{1}}\left[\frac{t_{1}}{2 R_{2}}+\left(\operatorname{inv} \phi-i n v \phi^{\prime}\right)\right]} \\
=\frac{\pi}{N_{1}}
\end{array}
$$

Rearranging this equation gives,

$$
\frac{t_{1}}{2 R_{1}}+\frac{R_{2}}{R_{1}} \frac{t_{2}}{2 R_{2}}=\frac{\pi}{N_{1}}+\left(1+\frac{R_{2}}{R_{1}}\right)\left(\operatorname{inv} \phi^{\prime}-\operatorname{inv} \phi\right)
$$

By substituting Eq. (7) and $2 R=N / P_{d}$ into the above equation and multiplying by $\mathrm{N}_{1} / \mathrm{P}_{\mathrm{d}}$,

$$
t_{1}+t_{2}=\frac{\pi}{P_{d}}+\frac{N_{1}+N_{2}}{P_{d}}\left(\text { inv } \phi^{\prime}-\operatorname{inv} \phi\right)
$$

By substituting Eq. (1) for $t_{1}$ and $t_{2}$,

$$
\begin{aligned}
& 2 e_{1} \tan \phi+\frac{p}{2}+2 e_{2} \tan \phi+\frac{p}{2} \\
& \frac{\pi}{P_{d}}+\frac{N_{1}+N_{2}}{P_{d}}\left(\operatorname{inv} \phi^{\prime}-\operatorname{inv} \phi\right)
\end{aligned}
$$

Simplifying the equation above gives,

$$
2 \tan \phi\left(e_{1}+e_{2}\right)+p=\frac{\pi}{P_{d}}+\frac{N_{1}+N_{2}}{P_{d}}\left(\text { inv } \phi^{\prime}-\text { inv } \phi\right)
$$

By substituting $p=\pi / P_{d}$ and solving for inv $\phi$,

$$
\operatorname{inv} \phi^{\prime}=\operatorname{inv} \phi+\frac{2 P_{d}\left(e_{1}+e_{2}\right) \tan \phi}{N_{1}+N_{2}}
$$

or

$$
e_{1}+e_{2}=\frac{\left(N_{1}+N_{2}\right)\left(\operatorname{inv} \phi^{\prime}-\operatorname{inv} \phi\right)}{2 P_{d} \tan \phi}
$$

Expressing the above equation in metric units with $\mathrm{m}$ as module,

$$
e_{1}+e_{2}=\frac{m\left(N_{1}+N_{2}\right)\left(\operatorname{inv} \phi^{\prime}-\operatorname{inv} \phi\right)}{2 \tan \phi}
$$

In this study, we limit our investigation to the case that the hob cutter is advanced into the gear blank the same amount that it is withdrawn from the pinion, therefore, $e_{2}=-e_{1}$ and, from Eq. (17) or (18), $\phi^{\prime}=\phi$. Because there is no change in the pressure angle, $R_{1}^{\prime}=R_{1}$ and $R_{2}^{\prime}=R_{2}$, and the gears operate at the standard center distance. If the offsets are unequal $\left(e_{2} \neq-e_{1}\right)$ then the center distance must change. This problem is beyond the scope of this paper.

\section{Gear Transmission Model}

The computer program DANST was used for the dynamic analysis. The DANST model employs four torsional degrees of freedom to represent a typical gear transmission. The model includes driving pinion and driven gear, connecting shafts, motor, and load. The equations of motion were derived from basic gear geometry and elementary vibration principles. DANST predicts the dynamic response of a transmission for several parameters including dynamic load and tooth bending stress. In an earlier study, the predictions of the computer model compared very well with experimental observations (Oswald et al., 1991).

The dynamics of gear systems can be influenced considerably by the stiffness of the meshing gear teeth. A principal excitation for gear dynamics and vibration is the variation of this stiffness caused by teeth entering and leaving mesh. This stiffness variation is a primary cause of the time-varying component of gear transmission error. The gear transmission error analysis derived earlier by Lin et al. (1993a) was used in this study. A more upto-date formula by Cornell (1981) replaces the Lewis equation for tooth stress calculation. The latest version of DANST also adds the effect of extended tooth contact due to deflection of loaded teeth (Lin et al., 1993a).

A more detailed development of the dynamic model and tooth root stress calculation can be found from previous literature (Cornell, 1981, and Lin et al., 1993b). 


\section{Results and Discussion}

The DANST analysis was applied to a pinion and gear set with a velocity ratio of $3: 1$. Parameters for the gear set are given in table $I$.

Cutting gears with an offset hob affects the tooth thickness as discussed above. This fundamentally affects the meshing action and the transmission error. The effect of hob offset can be seen in Fig. 4. The hob offset has a considerable effect on the starting and ending of tooth contact. For example, for the zero offset case, tooth contact starts at the roll angle of $0.33^{\circ}$ and ends at $39.46^{\circ}$, while for an offset of $1.78 \mathrm{~mm}\left(0.07 \mathrm{in}\right.$.) $\left(e_{1}=-e_{2}=1.78\right.$ $\mathrm{mm}$ ), the contact starts at $7.30^{\circ}$ and ends at $44.75^{\circ}$. The theoretical contact ratio changes slightly from 1.623 for no offset to 1.616 for $1.78 \mathrm{~mm}$ offset.

Since the dynamic response of a gear transmission is excited by the static transmission error, we may expect the changes in the static transmission error observed above will be reflected in the dynamic tooth stress. This effect can be seen in Figs. 5 and 6. Figure 5 shows the dynamic tooth stress of a standard pinion and gear (no hob offset) operating at $10000 \mathrm{pm}$. The maximum pinion stress (255 MPa or $37 \mathrm{ksi}$ ) is significantly greater than the gear stress (181 MPa or $26.29 \mathrm{ksi}$ ).

Figure 6 shows the dynamic stress for similar gears as in Fig. 5 but with a hob offset of $1.42 \mathrm{~mm}$ (0.056 in.) which is the optimum value determined from the static procedure by Mabie. The maximum dynamic tooth stress of both pinion and gear have been reduced to $204 \mathrm{MPa}$ (29.62 ksi) and 177.5 MPa (25.76 ksi), respectively. The stress balance in the pinion and gear has been remarkably improved when compared to the case with no hob offset (Fig. 5), however, it is still not exactly balanced. In the figure, the maximum stress in both gears has been decreased which indicates the load capacity of this gear system has been increased.

From the parameters in table I, the undamped fundamental natural frequency of the sample gear transmission is calculated to be $20500 \mathrm{rmm}$. To evaluate the effect of hob offset on dynamic load and stress, a study was conducted for a range of offset values on sample gear sets operated at the resonant speed (20 500 rpm) and its submultiples. Figure 7 compares the maximum dynamic load and maximum dynamic tooth root stress of pinion and gear as a function of hob offset, when the gear transmission is operating at the resonant speed. Although the dynamic tooth load is affected very little by the offset, the dynamic tooth root stress for the pinion and gear are affected significantly. With no offset, the pinion tooth stress (379 MPa) is about 20 percent higher than the gear tooth stress ( $317 \mathrm{MPa})$. As the offset value increases, the tooth stresses of pinion and gear converge becoming equal when the offset value is about $1.91 \mathrm{~mm}(0.075 \mathrm{in}$.). The analy- sis was carried to a theoretical limit of $\mathrm{e}=1.98 \mathrm{~mm}$ ( $0.078 \mathrm{in}$.) at which the pinion teeth become pointed.

For actual gears, the designer must maintain a minimum tooth thickness at the tip to prevent tip breakage. The designer must also allow for an edge break at the tip and for manufacturing tolerances on all dimensions. These factors are ignored in this analysis.

It is not possible to design a gear set with tooth stress exactly equal for the pinion and gear at all operating conditions. Figure 8 is similar to Fig. 7 except the operating speed is one-half resonant speed (10 $250 \mathrm{rpm})$. The dynamic load decreases slightly as the offset is increased. The maximum pinion and gear tooth stress approach each other as the hob offset increases to the limiting value $(e=$ $1.98 \mathrm{~mm}$ ) when the pinion teeth become pointed. In this case, the best value to equalize the dynamic tooth stress of pinion and gear is the maximum allowable hob offset.

From Figs. 7 and 8, we can see the operating speed plays an important role in determining the best offset values. We investigated the amount of hob offset required to equalize the dynamic tooth stress of pinion and gear at various operating speeds. Results are depicted in Fig. 9. At lower speeds, from 1000 to $6000 \mathrm{rpm}$, the required hob offset fluctuates irregularly between $1.40 \mathrm{~mm}(0.055 \mathrm{in}$.) and $1.98 \mathrm{~mm}(0.078 \mathrm{in}$.). For the range of 6000 to $20000 \mathrm{rpm}$, the offset value is limited by pinion tooth pointing at $1.98 \mathrm{~mm}$. Above $20000 \mathrm{rpm}$, the hob offset fluctuates as in the lower speed range. The maximum allowable offset $(1.98 \mathrm{~mm})$ is shown as a dashed line in the figure.

In Fig. 9, There is no obvious trend to determine the best offset value for gears which operate over a wide speed range. However, a weighted average of the hob offset values over the intended operating speed range can be used as an optimum value. For example, if the operating speed range for the sample gears is between 1000 and $6000 \mathrm{rpm}$, a hob offset of $1.78 \mathrm{~mm}(0.070 \mathrm{in}$.), which is a simple average of the offset values within the range, can be applied to minimize the difference in dynamic tooth strength of the pinion and gear. If the speed range is from 6000 to $20000 \mathrm{rpm}$, then the best offset is the maximum allowable value, $\mathrm{e}=1.98 \mathrm{~mm}$.

Figures 10 to 12 compare the dynamic response for the sample gears with hob offset values of $0,1.42,1.78$ and $1.98 \mathrm{~mm}$ over the speed range 1000 to $24000 \mathrm{rpm}$. In Fig. 10 we have the trend of the dynamic load. There is little difference in the dynamic load curves for hob offsets $\mathrm{e}=1.42,1.78$ and $1.98 \mathrm{~mm}$. All of these curves show a considerable reduction in dynamic load at most speeds over the no-offset curve except near and above the resonant speed of $20000 \mathrm{rpm}$ where there is little difference. The dynamic load curve of the optimal static offset $(1.42 \mathrm{~mm})$ appears to be slightly higher than the other two offset curves in the speed range below $14000 \mathrm{rpm}$. 
Figure 11 shows the maximum dynamic tooth stress for the pinion as a function of operating speed. The curves show that, at all speeds, any of the values of hob offset reduce the maximum pinion tooth stress. The stress is lower due to the increase in the pinion tooth thickness as well as the reduced transmission error. The dynamic stress reduction is especially significant at the system resonant speed (20 500 rpm) and its submultiples. For example, at resonant speed, the pinion dynamic stress declines from 389 to $341 \mathrm{MPa}$ ( 56.36 to $49.45 \mathrm{ksi}$ ), a 14 percent reduction. At one-half resonant speed, the stress changes from 296 to $214 \mathrm{MPa}$ ( 43 to $31 \mathrm{ksi}$ ), a 28 percent reduction. At one-third resonance, the stress decreases from 248 to $172 \mathrm{MPa}$ (36 to $25 \mathrm{ksi}$ ), a 30.5 percent reduction. As in the dynamic load curves, there is little difference in the stress for the two higher values of hob offset (1.78 and $1.98 \mathrm{~mm}$ ). However, there is a significant difference in the stress (up to 12 percent lower) between the curve for the $1.98 \mathrm{~mm}$ (maximum allowable) offset and the 1.42 mm (optimal static) offset.

Figure 12 shows the maximum dynamic tooth stress for the gear. The hob offset has much less effect on the gear than the pinion (Fig. 11). There is a moderate stress reduction in the speed range of 10000 to $18000 \mathrm{rpm}$, but there is a small increase in the stress for speeds above resonance.

The analysis procedure presented in this paper can be used to determine the best hob offset for balanced dynamic tooth strength. The actual offset amount applied to the manufacturing of the pinion and gear should depend upon the intended operating speed range of the gear pair.

\section{Conclusions}

A new version of the NASA gear dynamics code DANST (Dynamic ANalysis of Spur Gear Transmissions) was used to study the dynamic stress of nonstandard spur gears cut with offset hobs. The study was limited to gear pairs with an equal but opposite amount of hob offset applied to the pinion and gear to maintain the standard center distance. The operating speed of the transmission was varied over a broad range to evaluate speed effects on the dynamic response. The following conclusions were obtained from the investigation:

1. Cutting gears with offset hobs is an effective way to balance the dynamic tooth strength of the pinion and gear. In some cases, it reduces the dynamic stress in the pinion and increases stress in the gear to achieve balance, however, in other cases, the stress is reduced in both the pinion and gear which further improves the load capacity.

2. In general, increasing the offset improves the balance in dynamic tooth strength. However, the best hob offset value varies with the transmission speed. In many situations, the best offset value is limited by the maximum allowable offset that renders the pinion tooth pointed. The optimal offset determined from Mabie's static procedure is most effective at lower speeds.

3. For gears operating over a range of speeds, a suitable offset is the average of all the best values within this speed range.

4. The analysis developed in this study can be used to determine the required hob offset to balance the dynamic tooth strength of pinion and gear. The balanced design will provide a gear system with higher load capacity.

\section{$\underline{\text { References }}$}

1. Cornell, R., 1981, "Compliance and Stress Sensitivity of Spur Gear Teeth," ASME Journal of Mechanical Design, Vol. 103, No. 2, pp. 447-459.

2. Lin, H.H., Townsend, D.P., and Oswald, F.B., 1989, "Dynamic Loading of Spur Gears with Linear or Parabolic Tooth Profile Modifications," Proc. of ASME 5th Int'1 Power Trans. and Gearing Conf., Chicago, Illinois, Vol. 1, pp. 409-419.

3. Lin, H.H., Wang, J., Oswald, F.B., and Coy, J.J., 1993a, "Effect of Extended Tooth Contact on the Modeling of Spur Gear Transmissions," AIAA Paper 93-2148, AIAA/SAE/ASME/ASEE 29th Joint Propulsion Conference, Monterey, California.

4. Lin, H.H., Lee, C., Oswald, F.B., and Townsend, D.P., 1993b, "Computer-Aided Design of High-ContactRatio Gears for Minimum Dynamic Load and Stress," ASME Journal of Mechanical Design, Vol. 115, pp. 171-178.

5. Mabie, H.H., Walsh, E.J., and Bateman, V.I., 1983, "Determination of Hob Offset Required to Generate Non-Standard Spur Gears with Teeth of Equal Strength," Mechanism and Machine Theory, Vol. 18, No. 1, pp. 181-192.

6. Mabie, H.H. and Reinholtz, C.F., 1987, "Mechanisms and Dynamics of Machinery," Chapter 5, Fourth edition, John Wiley \& Sons, Inc., New York.

7. Mabie, H.H., Rogers, C.A., and Reinholtz, C.F., 1990, "Design of Nonstandard Spur Gears Cut by a Hob," Mechanism and Machine Theory, Vol. 25, No. 6, pp. 635-644.

8. Oswald, F.B., Rebbechi, B., Zakrajsek, J.J., Townsend, D.P., and Lin, H.H., 1991, "Comparison of Analysis and Experiment for Dynamics of Low-Contact-Ratio Spur Gears," Proc. of ASME 13th Biennial Conference on Mechanical Vibration and Noise, Miami, Florida, pp. 263-269. 
9. Oswald, F.B., Lin, H.H., Liou, C.H., and Valco, M.J., 1993, "Dynamic Analysis of Spur Gears Using Computer Program DANST," AIAA Paper 93-2295, ALAA/SAE/ASME/ASEE 29th Joint Propulsion Conference, Monterey, California.

10. Shigley, J.E., and Mitchell, L.D., 1983, "Mechanical Engineering Design," 4th edition, Chap. 13, McGraw-Hill Book Company.
11. Walsh, E.J., and Mabie, H.H., 1971, "A Simplified Method for Determining Hob Offset Values in the Design of Nonstandard Spur Gears," Proc. of 2nd Applied Mechanism Conference, Oklahoma State University, Stillwater, Oklahoma, pp. 23-1 to 23-18.

\section{TABLE I.-GEAR PARAMETERS}

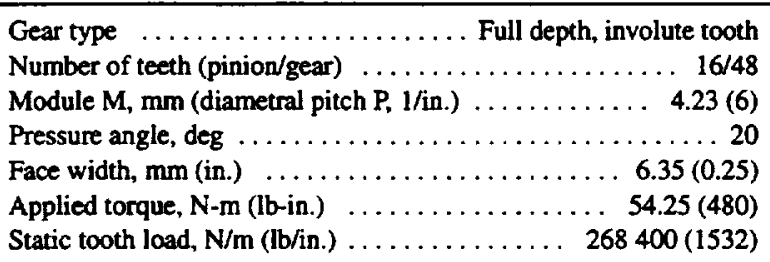




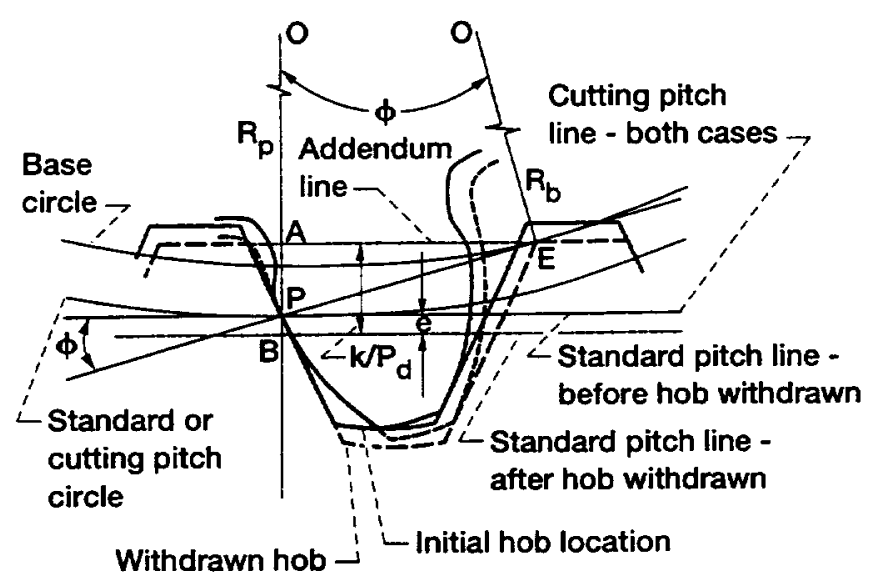

Figure 1.-Spur gear tooth cut by a standard hob or a withdrawn hob. From Mabie and Reinholtz (1987).

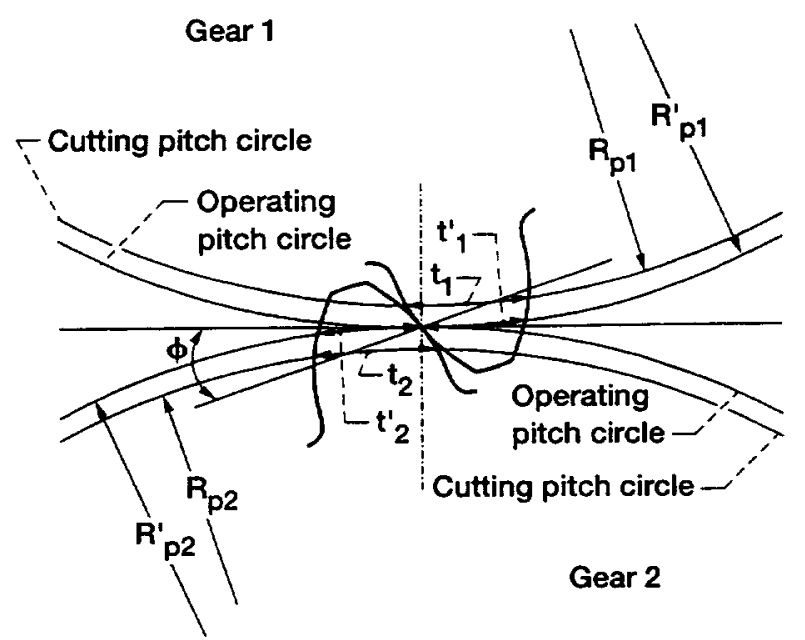

Figure 3.-Operating pitch circle, tooth thickness, and pressure angle of gears cut by offset hobs. From Mabie and Reinholtz (1987).

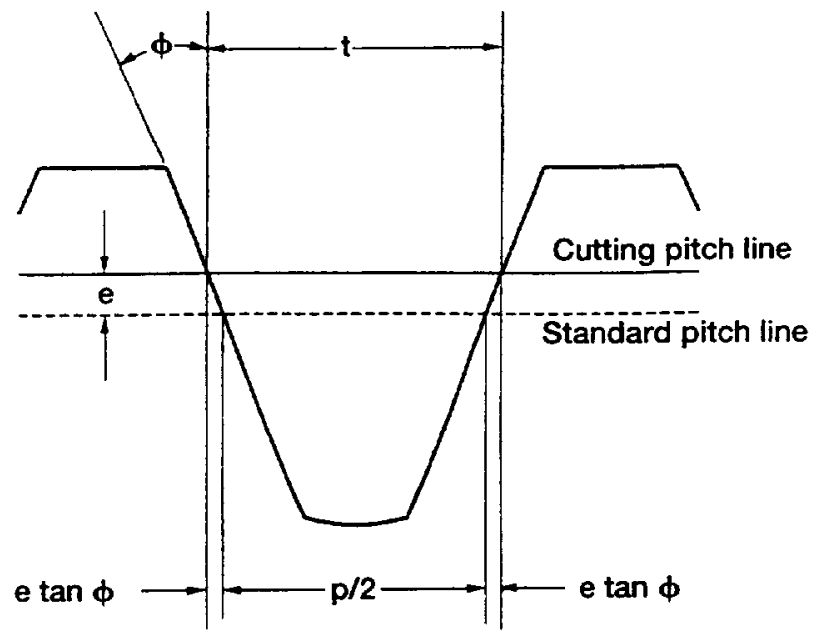

Figure 2.-Calculation of the enlarged tooth width of pinion cut by a withdrawn hob. From Mabie and Reinholtz (1987).

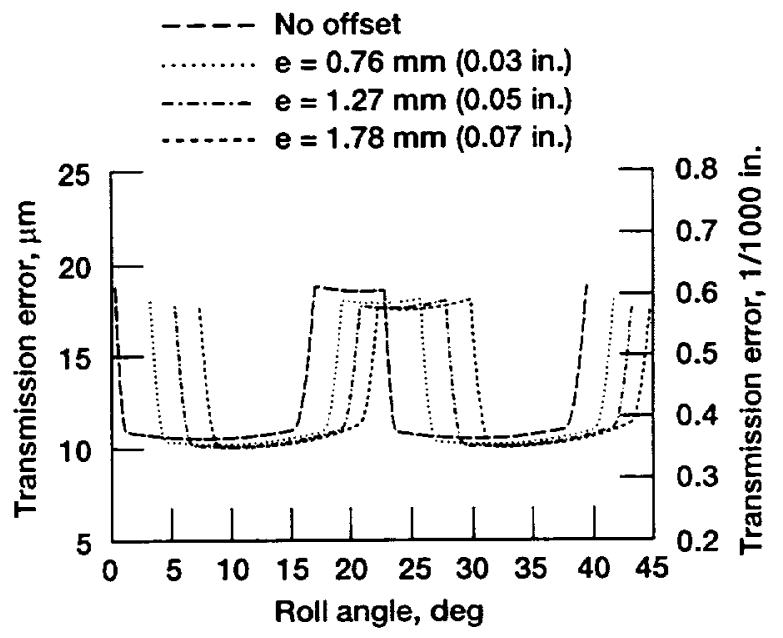

Figure 4.-Gear transmission error under static loading at different hob offset values. 


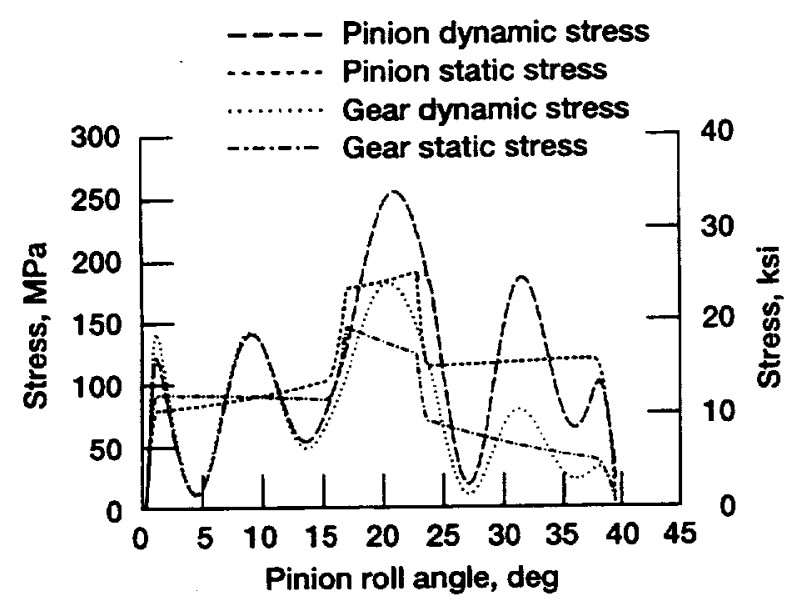

Figure 5. Static and dynamic tooth stress of pinion and gear at $10000 \mathrm{rpm}$, no hob offset.

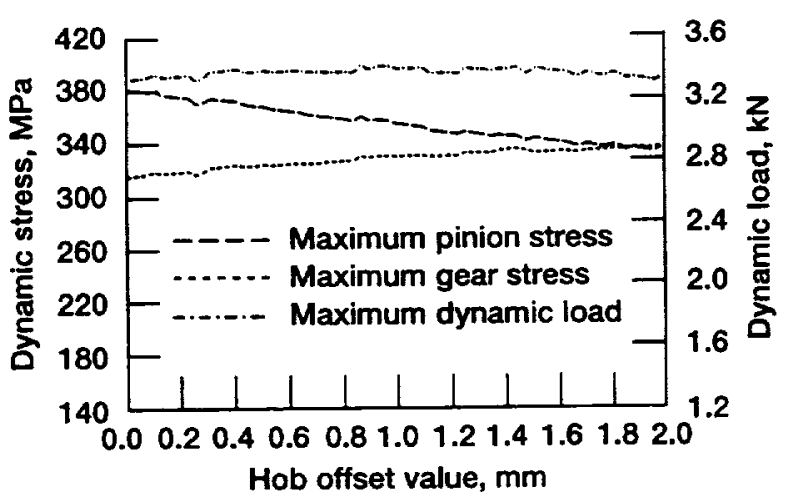

Figure 7.-Effect of hob offset value on dynamic load and stress of pinion and gear, at resonant speed (20 $500 \mathrm{rpm})$.

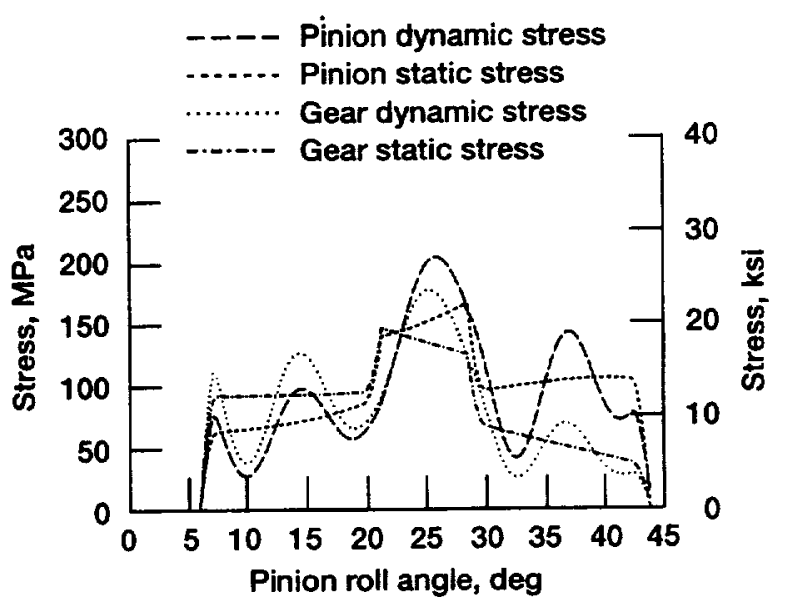

Figure 6.-Static and dynamic tooth stress of pinion and gear at $10000 \mathrm{rpm}$, with hob offset of $1.42 \mathrm{~mm}$.

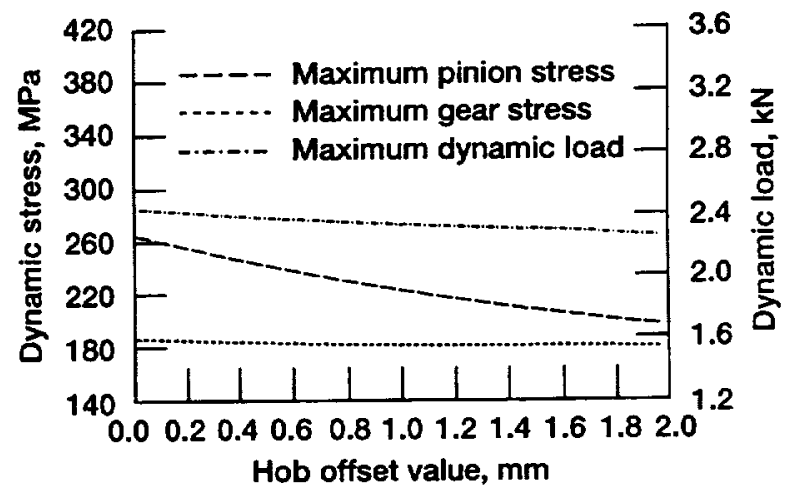

Figure 8.-Effect of hob offset value on dynamic load and stress of pinion and gear, at one-half resonant speed (10 $250 \mathrm{rpm}$ ). 


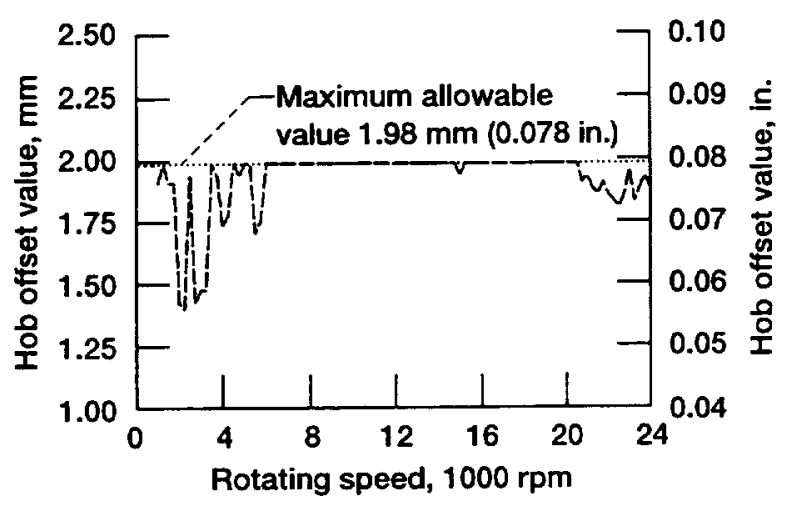

Figure 9.-Determination of best hob offset to balance dynamic tooth strength of pinion and gear at different speeds.

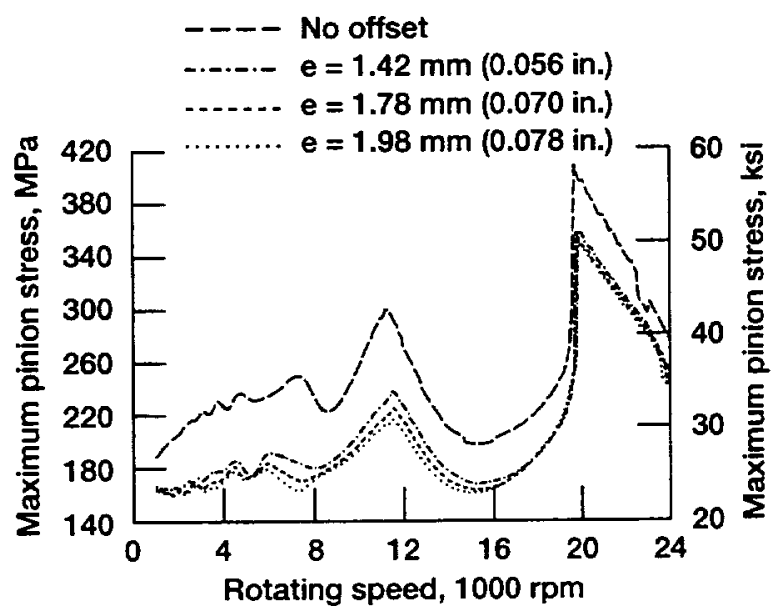

Figure 11.-Dynamic tooth stress of pinion as a function of speed, at various values of hob offset.

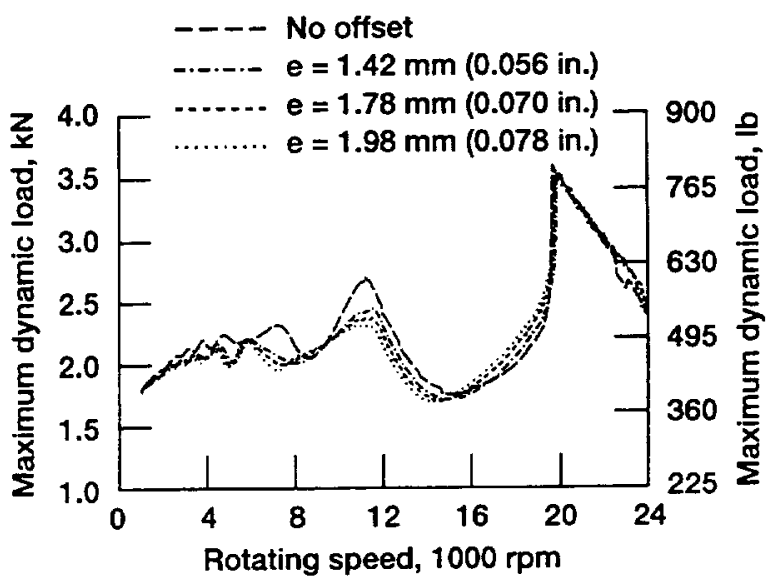

Figure 10.-Dynamic load of gears as a function of speed, with various values of hob offset.

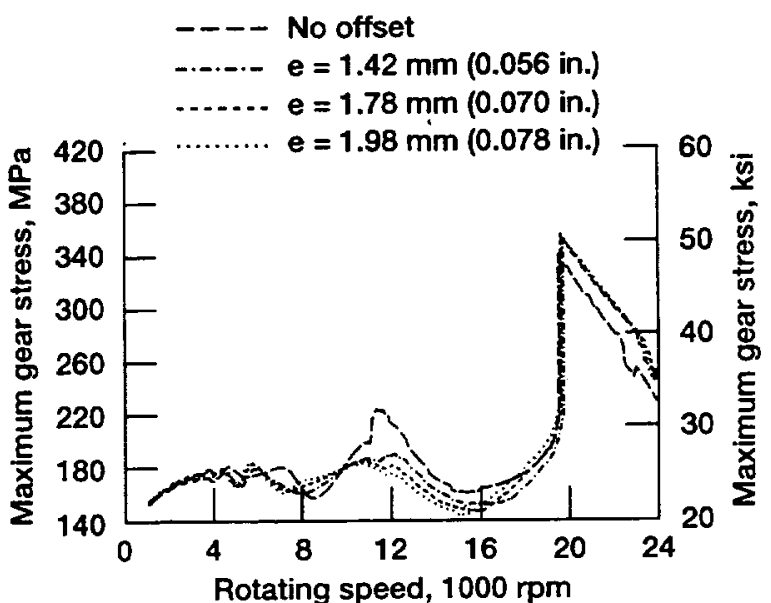

Figure 12.-Dynamic tooth stress of gear as a function of speed, at various values of hob offset. 


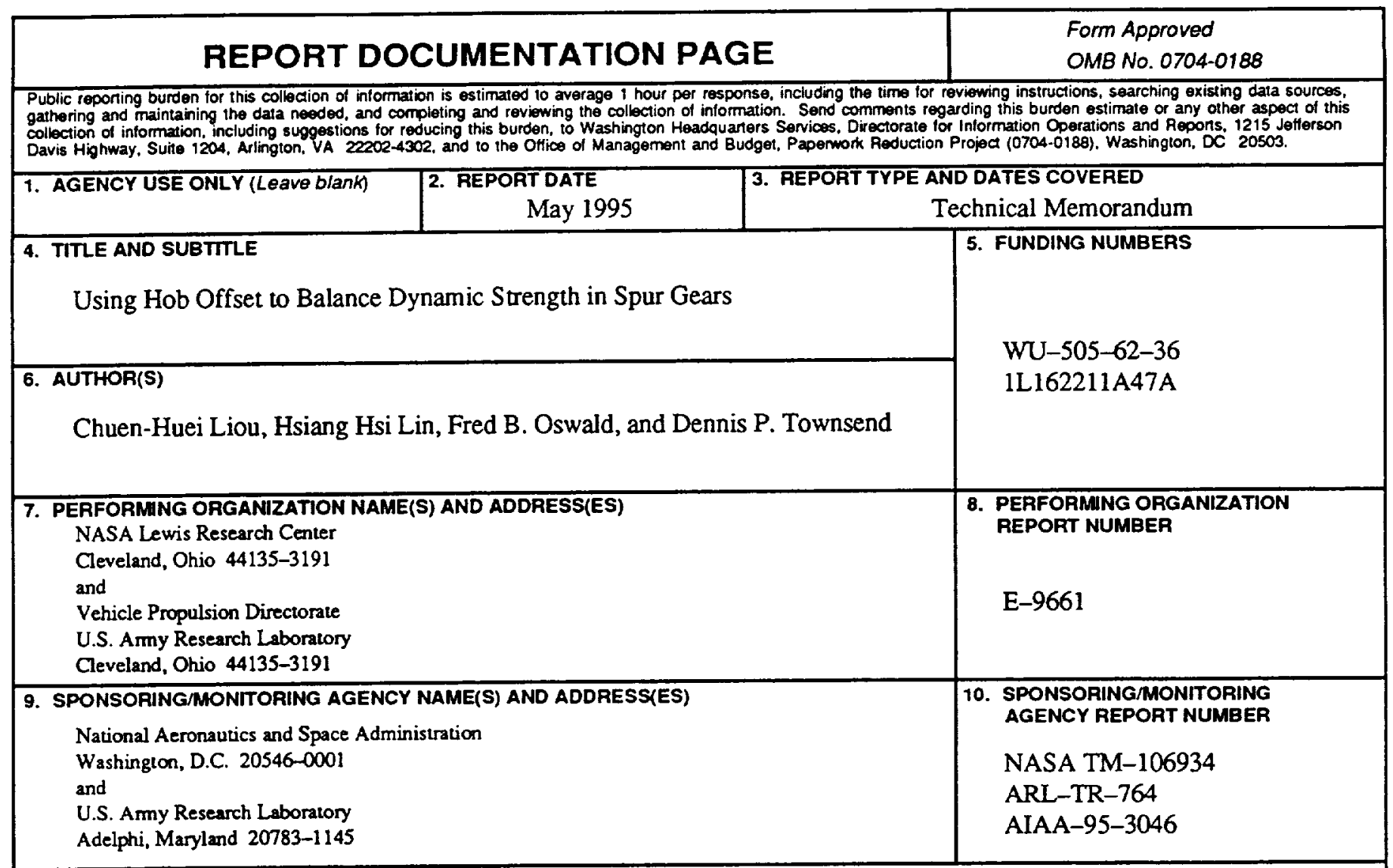

\section{SUPPLEMENTARY NOTES}

Prepared for the 31st Joint Propulsion Conference and Exhibit cosponsored by AIAA, ASME, SAE, and ASEE, San Diego, California, July 10-12, 1995. Chuen-Huei Liou and Hsiang Hsi Lin. The University of Memphis, Memphis, Tennessee 38152; Fred B. Oswald and Dennis P. Townsend, NASA Lewis Research Center. Responsible person, Fred B. Oswald, organization code 2730 , (216) $433-3957$.

Unclassified - Unlimited

Subject Category 37

This publication is available from the NASA Center for Aerospace Information, (301) 621-0390.

13. ABSTRACT (Maximum 200 words)

This paper presents an analytical study on the effect of hob offset on the dynamic tooth strength of spur gears. The study was limited to equal and opposite offset values applied to the pinion and gear to maintain the standard operating center distance. The analysis presented in this paper was performed using a new version of the NASA gear dynamics code DANST. The operating speed of the transmission has a significant influence on the amount of hob offset required to equalize the dynamic stresses in the pinion and gear. In the transmission studied, at low speeds, the optimum hob offset value was found to fluctuate. At higher speeds, the optimum value was constrained by the minimum allowed thickness at the tip of the pinion tooth. For gears that must operate over a range of speeds, an average offset value may be used. Spur gears designed with the procedure presented here can have significant improvements in load capacity.

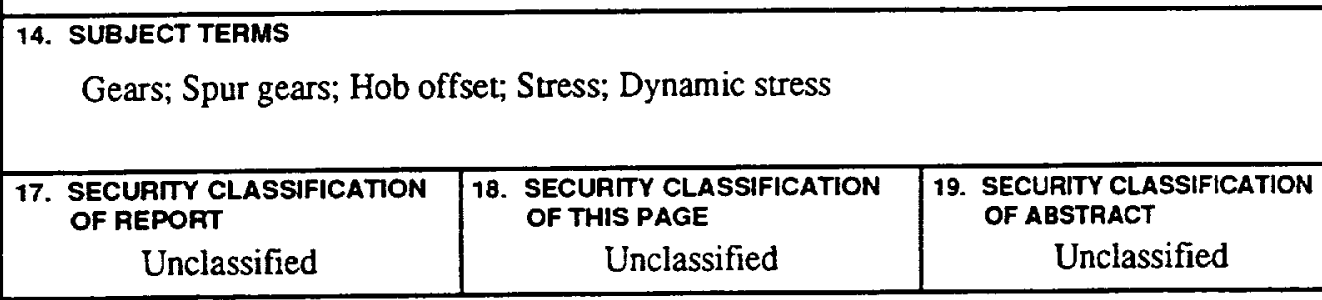

